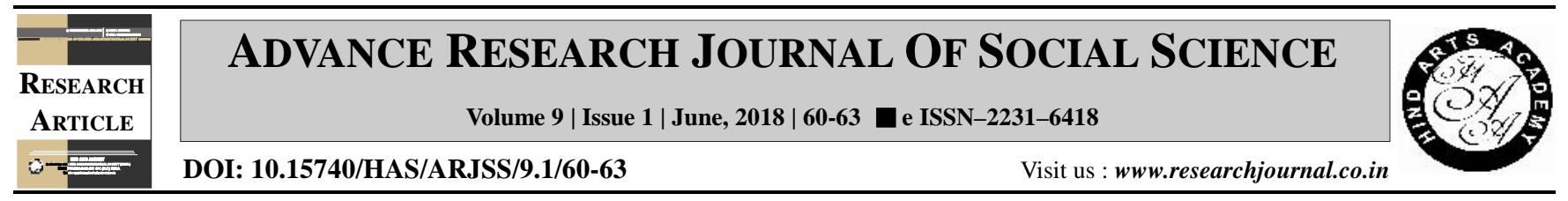

\title{
A study on psychological well-being during middle and late adulthood periods
}

Tulika Borah* and Minoti Phukan

Department of Human Development and Family Studies, College of Community Science, Assam Agricultural University, Jorhat (Assam) India

(Email: tulika.baruah@gmail.com)

\begin{tabular}{lrl}
\multicolumn{2}{l}{ ARTICLE INFO : } \\
Received $\quad:$ & 22.01 .2018 \\
Revised & $:$ & 29.04 .2018 \\
Accepted & $:$ & 16.05 .2018
\end{tabular}

KEY WORDS :

Psychological well-being, Aging, Middle adults, Late adults

HOW TO CITE THIS ARTICLE :

Borah, Tulika and Phukan, Minoti (2018).

A study on psychological well-being during middle and late adulthood periods. Adv. Res. J. Soc. Sci., 9 (1) : 60-63, DOI: 10.15740/HAS/ARJSS/9.1/60-63.

Copyright@2018 : Hind Agri -

Horticultural Society

*Author for correspondence

\begin{abstract}
Well-being is said as a good or satisfactory condition of existence; a state characterized by health, happiness, and prosperity. Psychological well-being refers to how people evaluate their lives. It is the combination of feeling good and functioning effectively. Recent psychological research has shown a shift from an emphasis on disorder and dysfunction to a focus on well-being and positive mental health. Since, in adult age many changes occur which may eventually induce psychological disturbances among them; the present study has been undertaken to assess the psychological well-being during middle and late adulthood periods. A total number of 120 samples were selected for the study. Ryff's scales of Psychological Well-being (Ryff, 1989 and Ryff and Keyes, 1995) was administered to collect the data. The results of the study revealed that the psychological well-being during middle and late adulthood periods was in average range and a significant difference in psychological well-being adults during middle and late adulthood periods were found.
\end{abstract}

